\title{
Redescription of Isotominella geophila Delamare Deboutteville, 1948 from Algeria (Collembola, Entomobryomorpha, Isotomidae), a second world record for an Ivory Coast species
}

\author{
Rafael Jordana $^{1,3}$, Salah Hamra-Kroua ${ }^{2} \&$ Enrique Baquero $^{1}$ \\ ${ }^{1}$ Department of Zoology and Ecology, University of Navarra, PO Box 177, 31080- \\ Pamplona, Navarra, Spain. \\ E-mails: ebaquero@unav.es, rjordana@unav.es \\ ${ }^{2}$ Laboratoire de Biosystématique et Écologie des Arthropodes, Université Mentouri \\ Constantine, Faculté SNV, Dépt. Biologie Animale, 25017 Constantine, Algérie. E- \\ mail: salahamra@yahoo.fr \\ ${ }^{3}$ Corresponding author. E-mail: rjordana@unav.es
}

\begin{abstract}
Isotominella geophila Delamare Deboutteville, 1948, from Massif Edough in Northeast Algeria, has been found for the second time and is redescribed. It is separated from all other genera of Isotomidae by the following combination of characters: absence of eyes and pigment, PAO oval, not subdivided, shorter than width of antennal base, dens partially crenulated, dental chaetotaxy with more than six setae $(13+4)$, posterior central S-setae on thoracic tergite II to abdominal tergite IV in p-row, S-seta on abdominal tergite V not thickened and mucro bidentate. This species exhibits sexual dimorphism.
\end{abstract}

\section{KEY WORDS}

Isotominae, new distribution, North Africa, Palaearctic Mediterranean fauna

\section{LIST OF ABBREVIATIONS}

as: anterior sensillum.

ms: microsensillum-a.

p-row: posterior row of setae on thoracic or abdominal tergites.

PAO: postantennal organ.

S: sensilla.

s: sensillum-a.

Slh: sublobal hairs. 


\section{INTRODUCTION}

The Edough massif has a Mediterranean climate, humid in the north and wet and cool in the south; in winter the average temperature is $6.5^{\circ} \mathrm{C}$ and in summer $24.6^{\circ} \mathrm{C}$. Total annual rainfall is $900-1400 \mathrm{~mm}$. The soil is a brown earth on steep slopes. The dominant plant species present are (in order of dominance): Quercus faginea ssp. mirbeckii, with an understory of Cytisus triflorus, Crataegus monogyna, Rubus ulmifolius and Rosa canina. In the humid areas Ilex aquifolium, Laurus nobilis, Viburnum tinus, Hedera helix and Smilax aspera are dominant.

The first survey of collembolan biodiversity in the Edough Massif in northern Algeria, was carried out between 1999 and 2007 and a rich fauna of Entomobryomorpha was found. The samples collected during this survey were from a Quercus faginea ssp. mirbeckii (zen oak) forest in the Edough massif (Fig. 1). Isotominella geophila Delamare Deboutteville, 1948 was found for the second time only since its first discovery on the Ivory Coast in these samples. It is redescribed here based on the material from North Africa. The genus is monobasic, belongs to Cryptopygus group and is related to Dagamaea Yosii, 1965.

\section{TYPE LOCALITY}

Original data: "Le Banco (C.I.) X 2, litière de souris, 7-VII-45, 2 ex. dont 1 adulte, type: Mus. Paris. - Azaguié T 29, 31-VIII-45 avec Acanthotermes acanthothorax, 1 ex. var. pilosa". Ivory Coast. The type material could not be found in Paris (L. Deharveng, personal communication).

\section{DIAGNOSIS}

Body elongate, without pigment; abdominal segments V-VI fused, separated from abdominal segment IV; anal spines absent; integument with primary granulation; eyes absent; PAO oval, neither divided nor constricted (Fig. 2B); antennal segment IV without apical bulb, sensilla slightly thickened, and with subterminal peg organ accompanied by a specialised curved seta (Fig. 2B, C); labrum with 2/554 setae (Fig. 2D); labial palp with rod-like A and B papillate setae (Fig, 2F); S-chaetotaxy: 33/22223(s), 10/100 (ms). Sensilla on abdominal tergite I-IV in p-row, except the lateral sensillum on abdominal tergite III, anterior to p-row; anterior S-setae (as) absent on abdominal tergite V (Fig. 3C); unguiculus present; furcal complex present; dens posterior basally crenulated; mucro bidentate.

\section{LOCALITY}

The specimens examined were found in Algeria on the Edough Massif, from moss on soil, taken in January 2002, collector Salah Hamra-Kroua, in the forest of Zen oak of Edough mountains (Seraidi village), located at $14 \mathrm{~km}$ in the North-West from Annaba town. Coordinates $36^{\circ} 55^{\prime} \mathrm{N}, 07^{\circ} 40^{\prime}$ E, elevation $750 \mathrm{~m}$. 


\section{MATERIAL EXAMINED}

One female and one juvenile on slide AR0VII02-06a; one male on slide AR0VII02-06b; one female on slide AR0VII02-09; two males on slide AR0VII02-12; one female on slide AR0VII02-13; six specimens in ethyl alcohol (AR0VII02-06-T). Material deposited in the Museum of Zoology, University of Navarra (MZNA).

\section{DESCRIPTION}

Body length: maximum $0.8 \mathrm{~mm}$ for males and 1.5 for females. Lacking pigment, integument with only primary granulation. Habitus elongate, abdominal V and VI fused, similar in length to the fourth (Fig. 2A). Eyes absent. PAO broad, not constricted, its length half the width of antennal segment I (Fig. 2B). Antennae slightly longer than head. Antennal segments I, II, III and IV ratio 1:1.5:1.5:2.7. Antennal segment I with two short ventro-external S-setae of equal length and width, and one basal minute microseta; antennal segment II with a distal ventro-external S-seta, and four basal microsetae; antennal segment III with the usual sensory organ with five S-setae (two bent) and without basal microsetae; antennal segment IV without apical bulb, one specialised curved sensilla near apex, with an adjacent peg, eight moderately thickened S-setae, and a basal microseta (Figs. 2B-C).

Labrum with 2 prelabral and 5,5,4 labral setae. Clypeus with four setae (Fig. 2D). Mandible slightly asymmetrical each with 3 or 5 teeth (Fig. 2E). Maxillary palp simple, with two sublobal hairs (slh following Potapov 2001), and a basal seta. Labial palp with rod-like A and B papillate setae, and 13 accessory guard labial setae (Fig. 2F). Labium with four proximal, four basomedial and five to six basolateral setae. Maxillary capitulum with two teeth; all lamellae, except lamella 5, longer than the capitulum (Fig. $2 \mathrm{G})$.

Tibiotarsus without $\mathrm{T}$ setae and without elongate or clavate tenent hair. Unguis without inner teeth, but with an external lateral tooth. Unguiculus present and with basal lamella (Fig. 3A).

Ventral tube with $6-7+6-7$ laterodistal and 4 posterior setae in males, $8-11+8-11$ laterodistal and 8 posterior setae in females. Retinaculum with $4+4$ teeth and one seta on corpus. Manubrium with 3-4+3-4 anterior setae in females, 1-2+1-2 in males, always with distal seta thickened, and with about 30-32 setae (females) and 26 (males) on posterior side. Dens with 13 setae on anterior side, and 4 setae on the crenulated part of posterior side (Fig. 3B). Mucro bidentate. Manubrium : dens : mucro ratio $=4: 4: 1$ (Fig. 3B).

The differences in the chaetotaxy of manubrium and ventral tube between females and males are constant (three females and three males studied), and may represent secondary sexual characters related to the size difference. 


\section{CHAETOTAZY}

The number of axial setae (rows) on tergites 15, 9 / 6, 4, 5, 7, 8. Macrosetae shorter than the tergite length and pointed, longest distally. Macrochaetotaxy: 1,1/3,3,3,4 on each side (Fig. 3C). Abdominal tergite $\mathrm{V}$ with 6 and VI with 13 macrosetae (Fig. 3D). Sensilla nearly as long as common setae. Sensillary formula: 3,3/2,2,2,2,3 (s), 1,0/1,0,0 (ms) (Fig. 3C). Medial accp-sens in p-row on thorax II to abdominal tergite IV; abdominal tergite III lateral sensilla anterior to p-row. Sensilla on abdominal tergite V not thickened, ventro-lateral one small and short, axial ones long, very similar to normal setae (Fig. 3D). No ventral setae on thorax.

\section{DISCUSSION}

The Cryptopygus complex is defined by the fusion of abdominal segments V and VI, presence of PAO, generally absence of anal spines and lack of morphological modification of abdominal segments V and VI (Rusek, 2002; Deharveng et al., 2005) It comprises the genera: Cryptopygus Willem, 1901, Hemisotoma Bagnall, 1949, Proisotomodes Bagnall, 1949, Cylindropygus Deharveng, Potapov and Bedos, 2005, Isotominella Delamare Debouteville, 1948 and Dagamaea Yosii, 1965. It is possible to separate Isotominella from the other genera by the dens morphology, smooth in Cryptopygus, Cylindropygus and Dagamaea, completely crenulated in Hemisotoma, and Proisotomodes, and only crenulated in the basal posterior half in Isotominella. Table 1 lists the important diagnostic characters for the genera of the Cryptopygus group.

\section{ACKNOWLEDGEMENTS}

We thank to Penelope Greenslade for providing helpful advice and corrections on a first draft, to Arturo H. Ariño for his help, and to Felipe N. Soto-Adames for his suggestions and corrections.

\section{REFERENCES}

- Bagnall, R.S. (1949) Contributions towards a knowledge of the Isotomidae (Collembola). 12(2), VIII, 84-87, XIV, 94-96.

- Deharveng, L., Potapov, M. \& Bedos, A. (2005) Cylindropygus ferox gen. n., sp. n.: A new member of the Cryptopygus complex (Collembola, Isotomidae) from central France. Journal of Natural History, 39 (23), 2179-2185.

- Delamare Debouteville, C. (1948) Recherches sur les Collemboles Termitophiles et Myrmécophiles (Écologie, Éthologie, Systématique) Archives de Zoologie Expérimentale et Générale, 85, 261-425.

- Potapov, M. (2001) Isotomidae. In: Dunger, W. (Ed), Synopses on Palaearctic Collembola, vol. 3. Abhandlungen und Berichte des Naturkundemuseums Görlitz, Band 73, Heft 2, pp.1-603. 
- Rusek, J. (2002) Do we have Cryptopygus-representatives (Collembola: Isotomidae) in Europe? Pedobiologia, 46, 302-310.

- Willem, V. (1901) Les Collemboles recueillis par l'Expédition antarctique belge. Annales de la Société Entomologique de Belgique, 45, 260-262.

- Yosii, R. (1965) On some Collembola of Japan and adjacent countries. Contribution from the Biological Laboratory Kyoto University, 19, 1-71. 


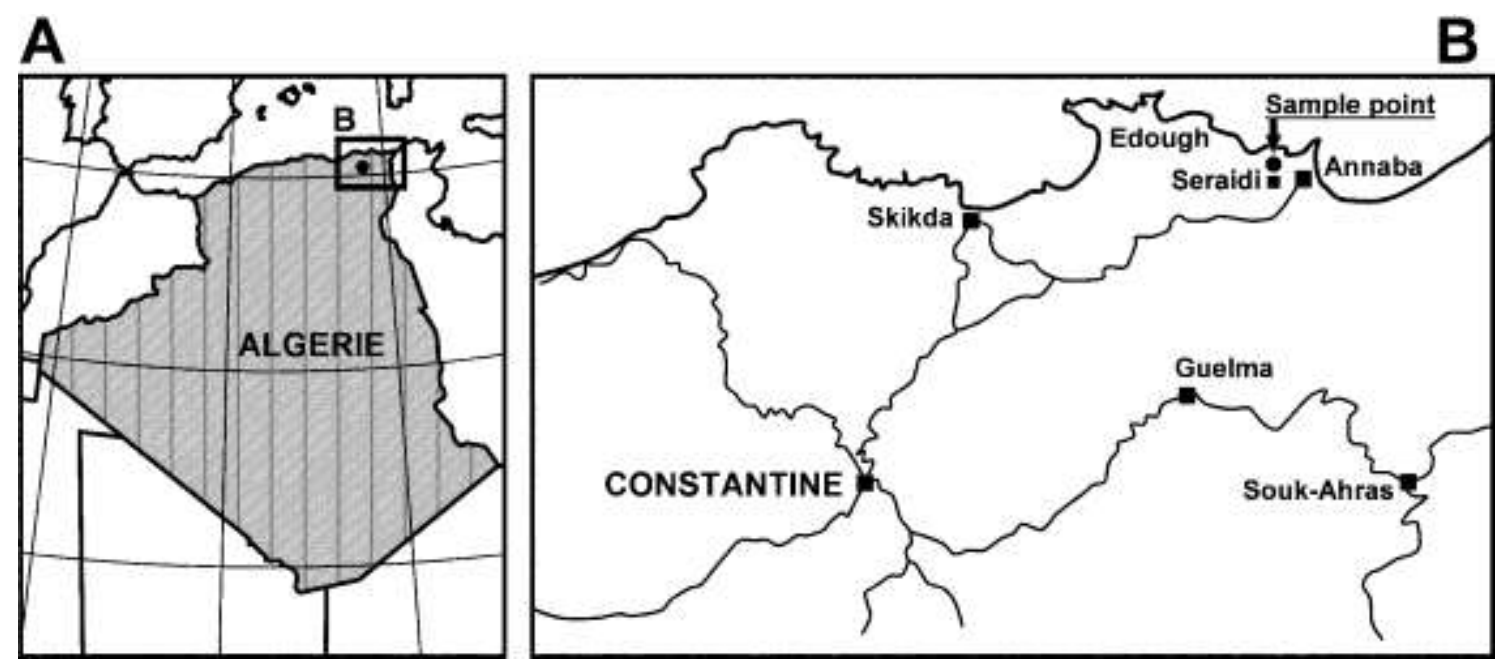

Figure 1. Study area with Edough massif indicated. 


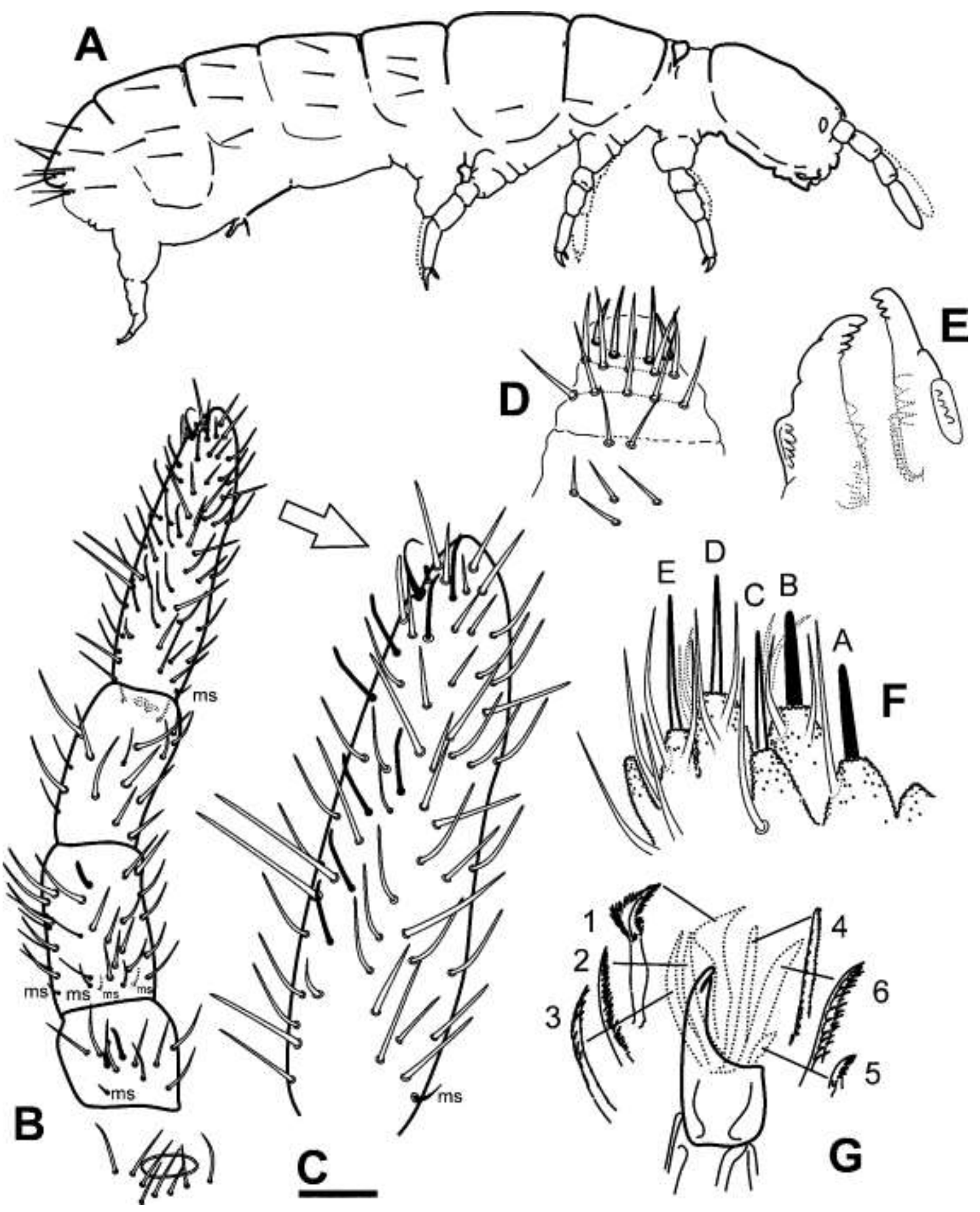

Figure 2. Isotominella geophila: A, habitus of a male specimen; $\mathbf{B}$, antenna, ventrolateral view, and part of the head showing the PAO and proximal setae (ms, microsensillum); $\mathbf{C}$, fourth antennal segment (bar: 10 micrometers); D, clypeus and labrum; E, mandibles; F, labial palp; G, maxilla. 


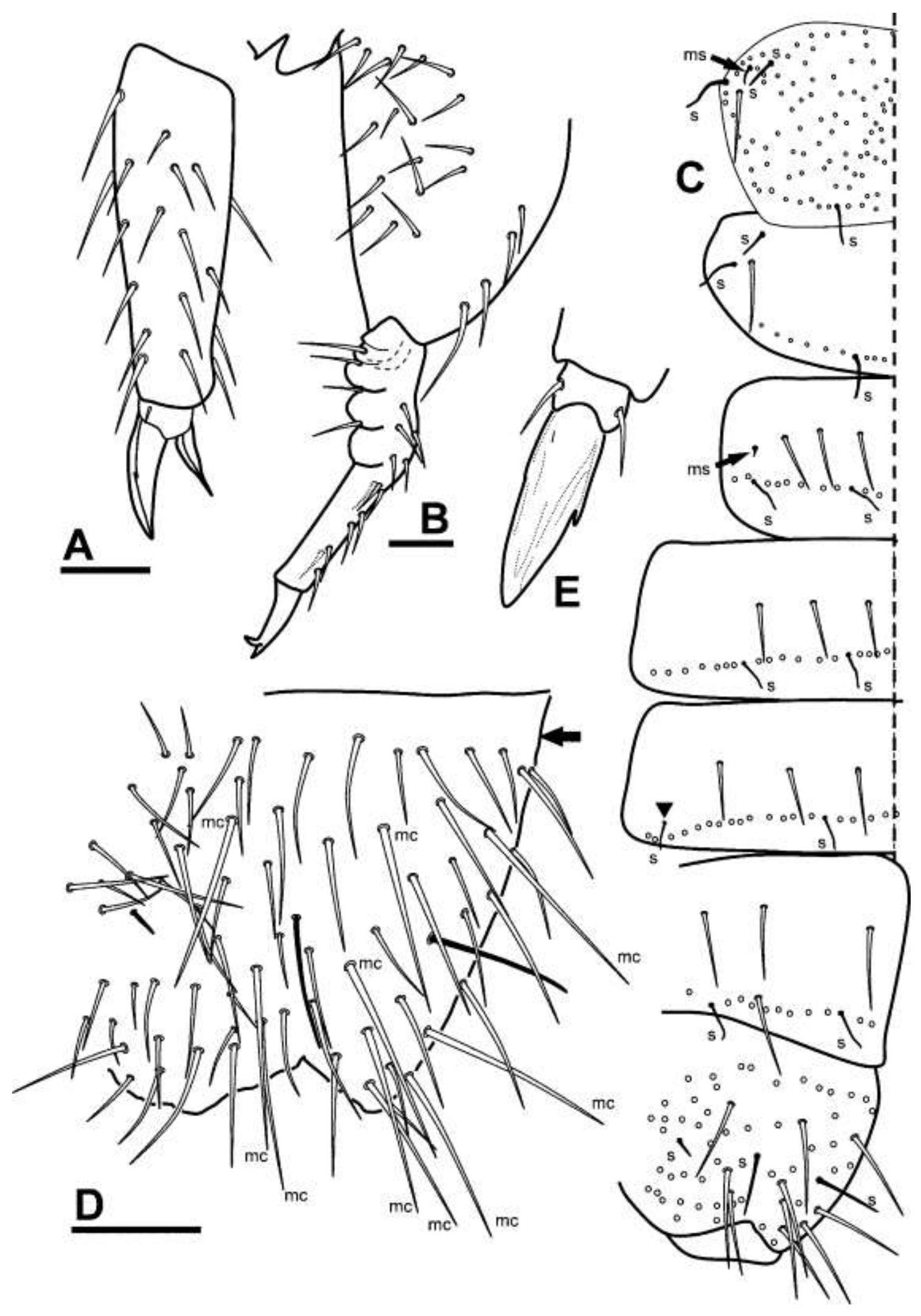

Figure 3. Isotominella geophila: A, tibiotarsus, unguis and unguiculus, lateral external view; B, furca in lateral view; $\mathbf{C}$, dorsal macrochaetotaxy (s, sensillum; ms, microsensillum); D, abdominal segments $\mathrm{V}$ and VI in lateral view (the arrow points the axis; mc, macroseta); E, unguis (dorsal view). Bar: 25 micrometers. 
Table 1. Comparative characters traditionally used for comparing the genera of the Cryptopygus complex and their relation co-ocurrence with I. geophila. Characters that differ from I. geophila in bold. * Denotes presence on some species in the genus only.

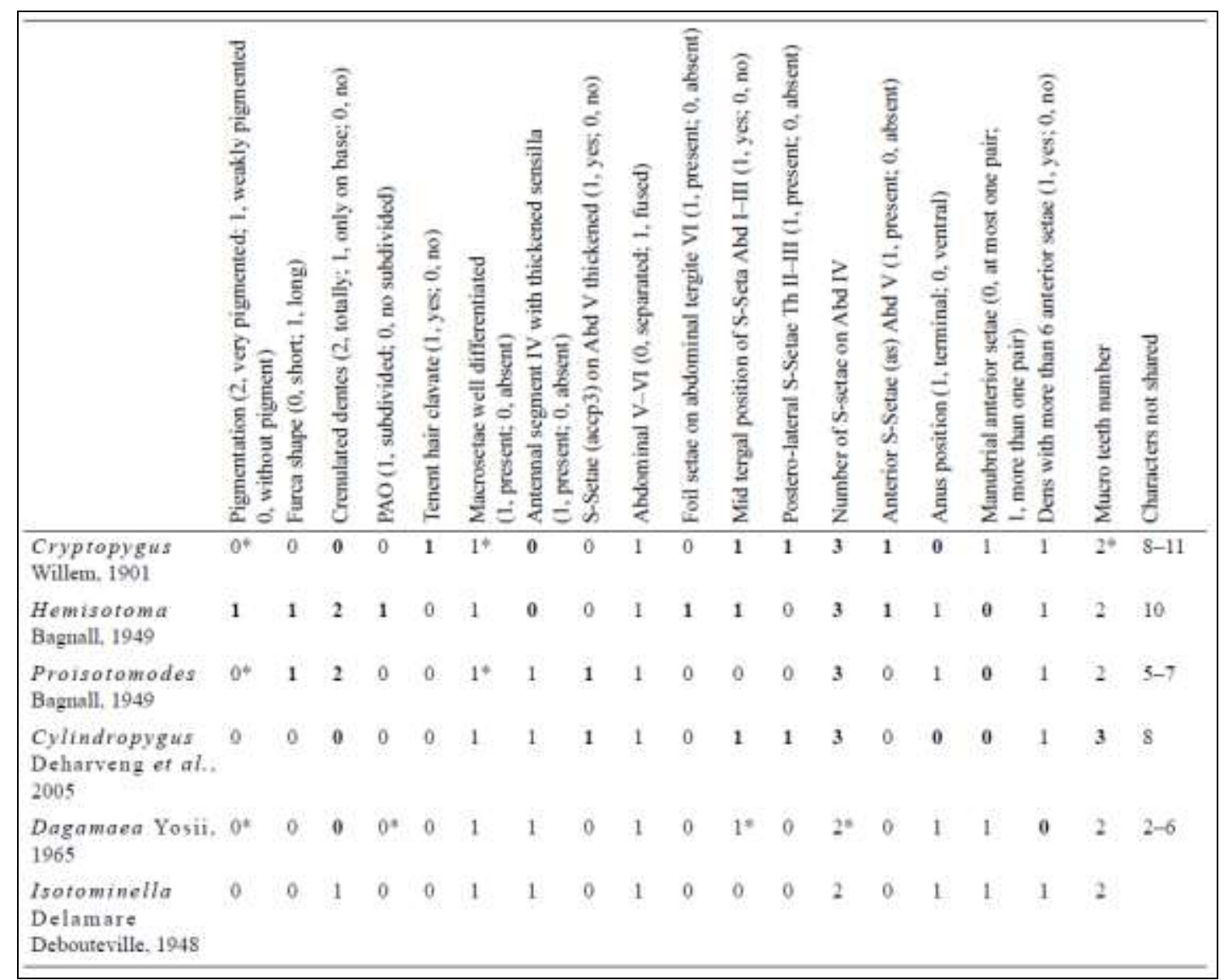

